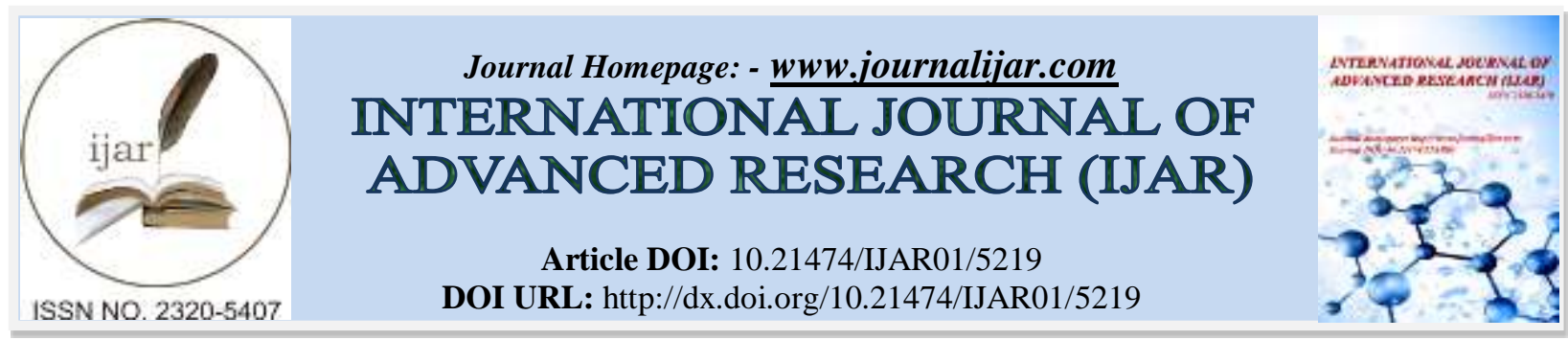

RESEARCH ARTICLE

\title{
KNOWLEDGE REGARDING VACCINATION AMONG THE MOTHERS ATTENDING MATERNAL AND CHILD HEALTH CENTRE, GOVT. MEDICAL COLLEGE, NAHAN, HIMACHAL PRADESH.
}

\author{
Dr. Sumita Kumari Sandhu ${ }^{1}$ and Dr. Raman Chauhan ${ }^{2}$. \\ 1. Asstt. Professor, Dr. Y. S. Parmar Govt., Medical College, Nahan. \\ 2. Asstt. Professor, Dr. R.P. Govt.,Medical College, Kangra at Tanda.
}

\section{Manuscript Info}

Manuscript History

Received: 19 June 2017

Final Accepted: 21 July 2017

Published: August 2017

Key words:-

MCH (Maternal and Child Health

Centre), Vaccine, Under Five.

\begin{abstract}
Background: Universal immunization against major vaccinepreventable diseases is one of the most cost-effective means of reducing under-five child morbidity and mortality.

Objective: The present study was done with the objective of assessment of knowledge regarding vaccination among the mothers of Under five children.

Material and methods: This study included a total of 105 mothers attending the MCH (Maternal and Child Health Centre), attached to the medical college, Nahan, Himachal Pradesh. The data were collected by using a structured questionnaire including demographic variables and questions related to the knowledge regarding vaccination.

Results: Almost 91.4\% mothers were aware of vaccination that vaccines are important to prevent the vaccine preventable diseases. $54 \%$ were not able to tell even a name of single vaccine. Study revealed that the $57.1 \%$ of the mothers quoted that their source of information related to the vaccination was health worker of nearest health centres. Study shows the significant association between the level of mother's education and socio economic status with the knowledge score of the mothers.

Conclusion: Most of the mothers were aware of vaccination but very few were able to tell the name of vaccines. Mothers were also not aware about the newer vaccines introduced in the schedule i.e. Rotavac. There is still need of strengthening the maternal and child health services to improve the overall health of the child.
\end{abstract}

Copy Right, IJAR, 2017,. All rights reserved.

\section{Introduction:-}

Universal immunization against major vaccine preventable diseases is one of the most cost-effective public health intervention in reducing under-five child morbidity and mortality. ${ }^{1}$ Globally 1.5 million children die every year from vaccine preventable diseases, and most of these deaths occur in the developing countries. ${ }^{2}$ Under the Universal Immunization Programme (UIP), significant achievements have been made in preventing and controlling the Vaccine Preventable Diseases (VPDs). Immunization has to be sustained as a high priority to further reduce the incidence of all VPDs, control measles, eliminate tetanus and eradicate poliomyelitis. 
Full immunization (i.e. received one dose of BCG, three doses of DPT, Hep-B, Hiv and OPV each and one dose of Measles before one year of age) gives a child the best chance for a healthy life. Preventing disease before it occurs saves money, energy, and lives. Immunization is a key strategy to child survival. By protecting infants from VPDs, immunization significantly lowers morbidity and mortality rates in children. ${ }^{3}$

Factors such as knowledge, attitude and practices of parents contribute to contribute to success or failure of immunizations program. Information about knowledge, attitude and practices about immunization is lacking in developing countries. ${ }^{4}$ Assessing immunization coverage helps to evaluate progress in achieving program objectives and in improving service deliver. The mother plays a major role in promoting the health of children. ${ }^{5}$

Assessing the knowledge and awareness regarding immunization among mothers plays major role in promoting the health of children. Several misconception, ignorance and inadequacy of knowledge in relation to vaccines are prevalent among mothers. There is need of a baseline study to evaluate the awareness of immunization among mothers.

\section{Methodology:-}

Study design: A cross sectional study was done to evaluate the knowledge and awareness regarding immunization among mothers.

Study setting: The study was conducted at the Maternal and Child Health Centre, Nahan which is attached as urban health training centre with the department of Community Medicine, Dr. Y.S. Parmar Govt. Medical College, Nahan, and District Sirmaur.

Study population: All attending mothers who were having under five children and attending the routine immunization clinic and willing to participate in the study.

Data collection: A structured questionnaire was designed after reviewing relevant literature. The data collection tool included demographic characteristics and ten questions related to the knowledge regarding immunization among mothers. It includes questions regarding knowledge of vaccine preventable disease, vaccine schedule, name of vaccines, side effects and contraindications of immunization, history of last vaccine received by the child, action taken if any side effect occurred, any newer vaccine introduced in the schedule, reason for the delay or non vaccination.

Scoring was done for the knowledge items, correct response was scored one grade and the incorrect zero. Scores of all items were summed up and divided by total number of items which gives mean score. The final score was converted into percent scores and quantitative values (mean and standard deviation) were calculated. Knowledge was considered good if percent score was above $60 \%$, average with percent score between $35-60 \%$ and poor if percent score below $35 \%$.

Data were analyzed using Statistical package for social sciences (SPSS) version 20. Descriptive analysis was done. Qualitative data were presented in mean and standard deviation and qualitative data were presented using frequency distribution. Chi square test was applied to find the association between the independent variables and knowledge regarding vaccination among mothers. $\mathrm{P}$ value of $<0.05$ was considered significant.

\section{Results:-}

This present study was conducted in Maternal and child health centre, Nahan in which a total of 105 mothers were assessed for their knowledge regarding immunization. Majority of mothers were in 25-29 years age group followed by $30-34$ years. $43 \%$ of mothers were educated up to secondary school followed by $25 \%$ up to high school. Table 1 shows the demographic profile of the study participants.

Table 1:- Socio demographic profile of study participants.

\begin{tabular}{|l|l|l|}
\hline Variable & Group & $\mathbf{N}(\boldsymbol{\%}) \mathbf{n}=\mathbf{1 0 5}$ \\
\hline Age of Mother & $20-24$ Years & $18(17.1)$ \\
& 25-30 Years & $56(53.3)$ \\
& 31-35 Years & $23(21.9)$ \\
\hline
\end{tabular}




\begin{tabular}{|l|l|l|}
\hline & $35-40$ Years & $8(7.6)$ \\
\hline Residence & Rural & $34(32.4)$ \\
& Urban & $71(67.6)$ \\
\hline Education of Mother & Illiterate & $02(1.9)$ \\
& Primary school & $07(6.7)$ \\
& Secondary school & $45(42.9)$ \\
& Above Secondary & $51(48.6)$ \\
\hline Occupation of Mother & Working & $18(17.1)$ \\
& Non working & $87(82.9)$ \\
\hline Socioeconomic status & Lower class & \multicolumn{1}{|c|}{$09(8.6)$} \\
& Lower middle & $25(23.8)$ \\
& Middle class & $36(34.3)$ \\
& Upper middle & $33(31.4)$ \\
& Upper class & \multicolumn{2}{|c|}{$02(1.9)$} \\
\hline Religion & Hindu & $95(90.5)$ \\
& Muslim & $9(8.6)$ \\
\hline
\end{tabular}

Knowledge regarding immunization among Mothers:-

Almost $91.4 \%$ mothers were aware of vaccination that vaccines are important to prevent the vaccine preventable diseases. $45.7 \%$ of mothers were able to tell the name of vaccines and $54 \%$ were not able to tell even a name of single vaccine. Fig 1 shows the source of information related to vaccination and $57.1 \%$ participants told that their source of information related to the vaccination was health resources which include health workers, ASHA, and AWW of nearest health centres.

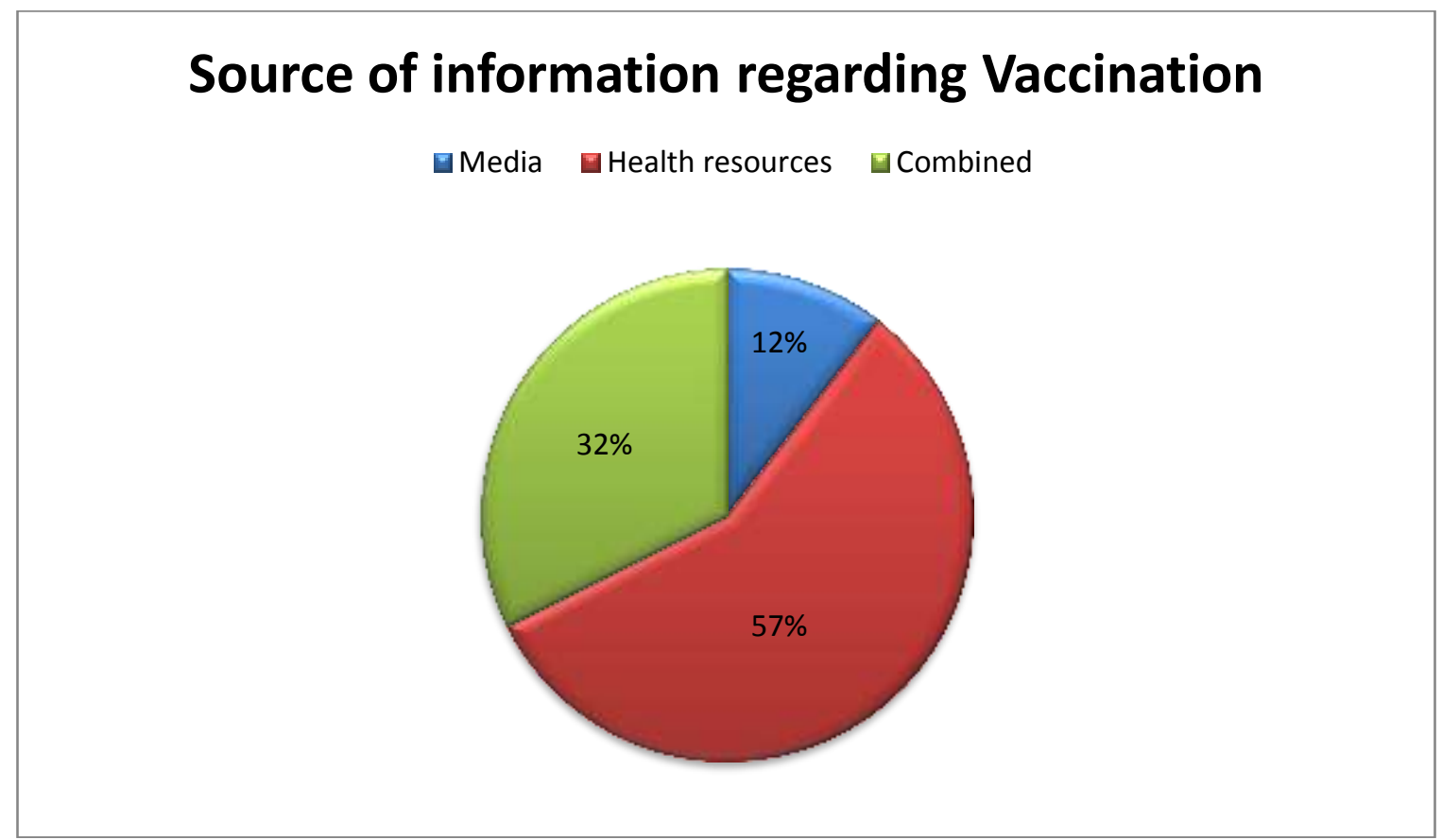

Fig 1- Source of information regarding Vaccination among Mothers

$42 \%$ of mothers gain the information related to time of each vaccination from health workers followed by $22 \%$ from Maternal and child protection card and 18\% from ASHA. 65\% of mothers know about the common side effects of vaccines like pain at the injection site, swelling, redness. $14.3 \%$ of mothers were reported the few contraindication for immunization like common cold, cough, diarrhea and fever. Fig 2 shows that $51.4 \%$ of mothers were aware of the name of last vaccination received by their child and $58.1 \%$ were also know about the side effects from the last vaccine received by the child. 


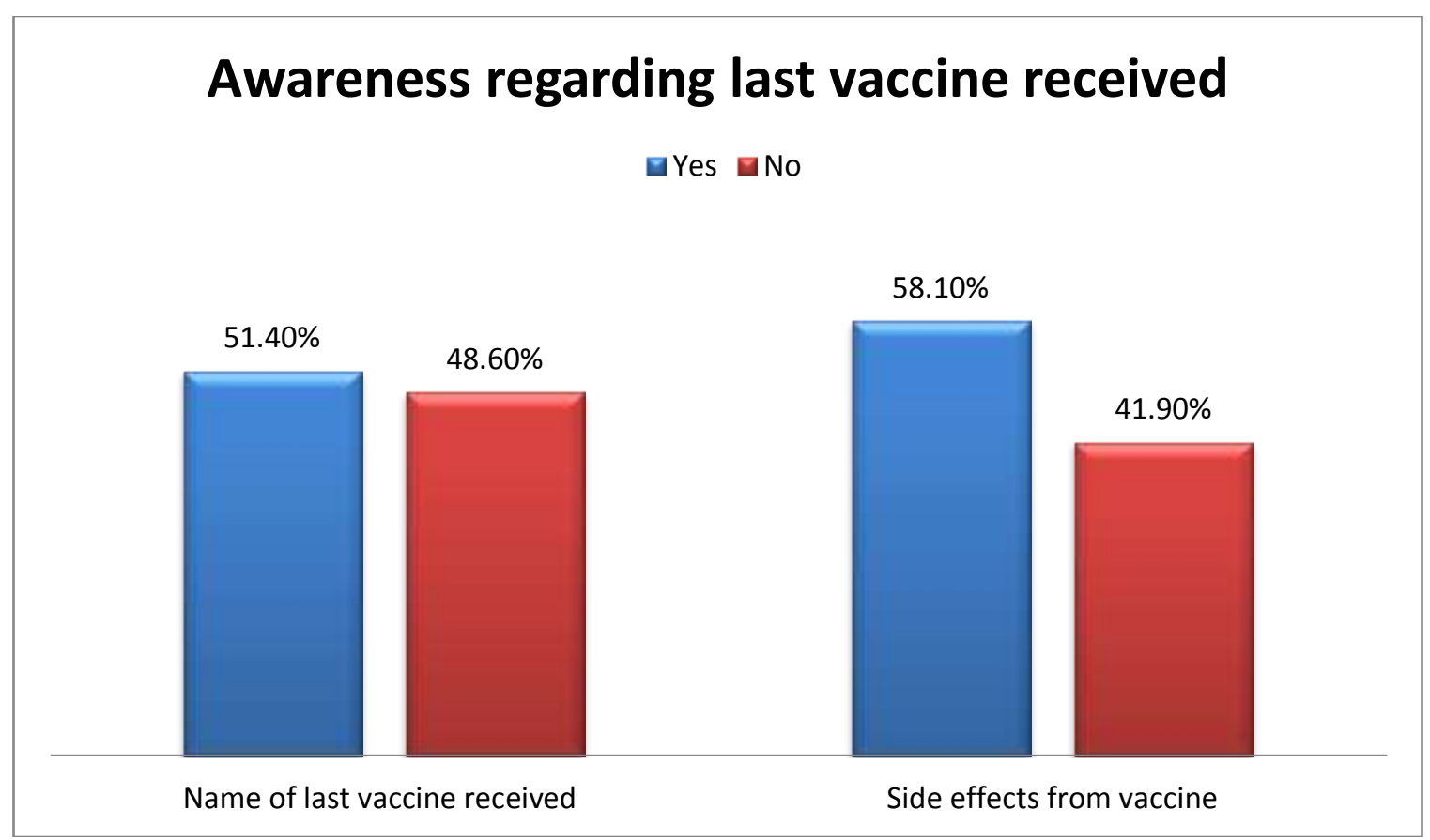

Fig 2- Awareness regarding last vaccine received and side effect of the vaccine.

Among all the mothers who had reported side effects from the last vaccination, $80.3 \%$ has given syrup paracetamol which was prescribed from the health centre after vaccination. $9.8 \%$ were those who reported side effect to the health facility and $9.8 \%$ of mothers have done nothing.

Only $18.1 \%$ of mothers were aware about the new vaccine Rotavac introduced in the schedule at $6,10,14$ weeks.

Mothers with the secondary and above education were significantly $(\mathrm{p}=0.003)$ had more knowledge regarding the vaccine preventable diseases. $60 \%$ of mothers with the secondary and above educational level were aware about the common side effects of the vaccination. Awareness regarding vaccine preventable diseases was $60 \%$ among urban area as compare to the $31.4 \%$ in the rural area.

Assessment of knowledge score regarding vaccination among mothers of under five children was categorize into 3 Good ( $>60 \%)$, Average (35\%-60\%), and Poor $(<35 \%)$. $44.8 \%$ of mothers attending the maternal and child health centre were had poor knowledge regarding the vaccination shown in fig 3. 


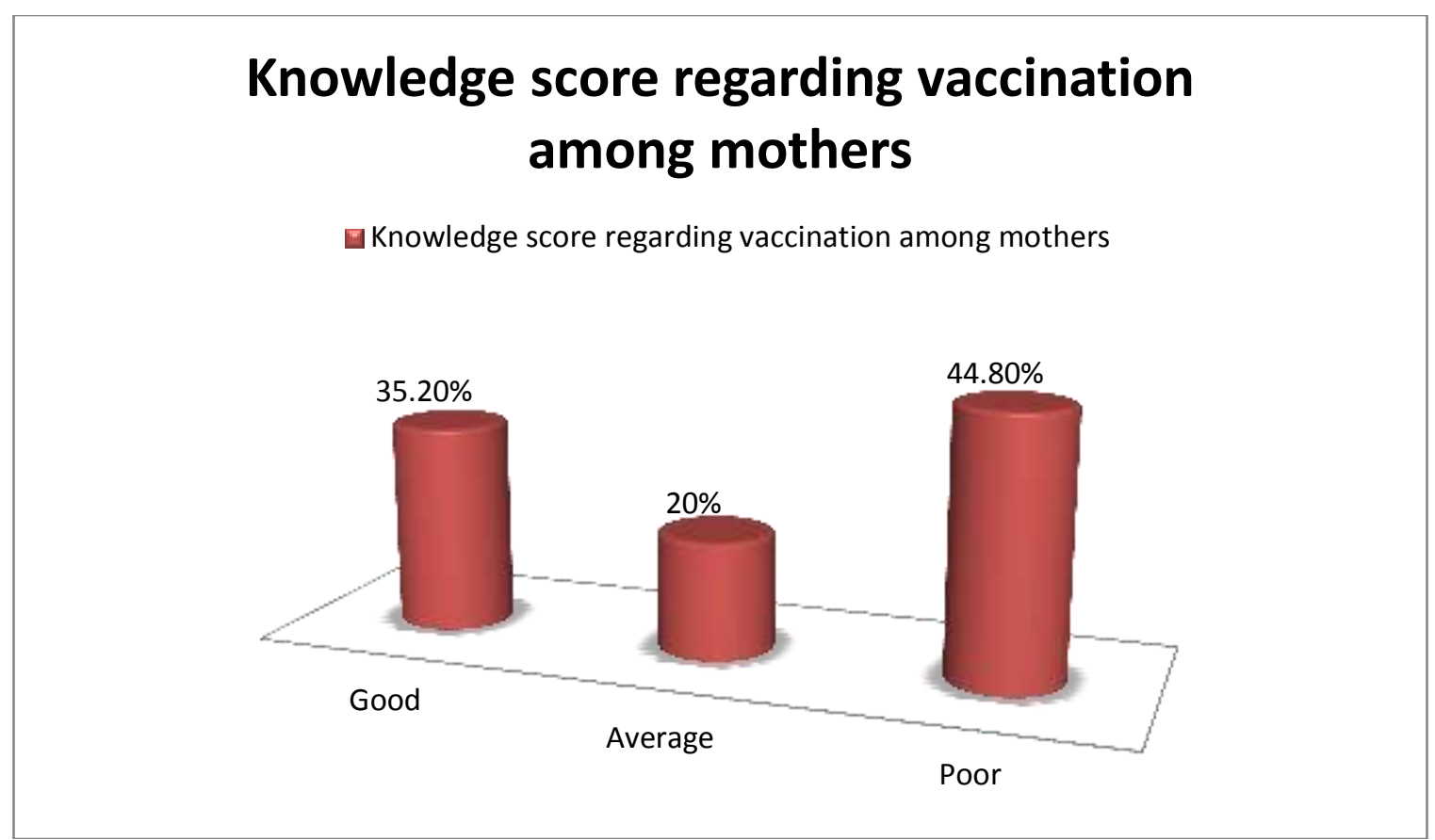

Fig 3:- Assessment of Knowledge score regarding vaccination among mothers.

The association between the socio demographic variable and knowledge score among mothers showed in table no 2 . Poor score was seen among mothers with low educational level as compare to the higher educational level. 30.5\% mothers who were residing in the urban area shows the poor knowledge score. This present study shows the significant association between the lower socio-economic status and poor knowledge score among mothers.

Table no 2:- Association between Socio-demographic variable \& Knowledge score

\begin{tabular}{|c|c|c|c|c|}
\hline \multirow{2}{*}{ Socio-demographic Variable } & \multicolumn{3}{|c|}{ Knowledge score among mothers } & \multirow{2}{*}{$\begin{array}{l}\chi^{2} \\
\text { p value }\end{array}$} \\
\hline & Good N (\%) & Average N (\%) & Poor N (\%) & \\
\hline $\begin{array}{l}\text { Mother's Education } \\
\text { Lower education } \\
\text { High education }\end{array}$ & $\begin{array}{l}15(14.3) \\
22(21.0)\end{array}$ & $\begin{array}{l}9(8.6) \\
12(11.4)\end{array}$ & $\begin{array}{l}30(28.6) \\
17(16.2)\end{array}$ & $\begin{array}{l}5.267 \\
\mathbf{0 . 0 5 2} *\end{array}$ \\
\hline $\begin{array}{l}\text { Mother's Occupation } \\
\text { Working } \\
\text { Non working }\end{array}$ & $\begin{array}{l}7(6.7) \\
30(28.6)\end{array}$ & $\begin{array}{l}4(3.8) \\
17(16.2)\end{array}$ & $\begin{array}{l}7(6.7) \\
40(38.1)\end{array}$ & $\begin{array}{l}0.303 \\
0.859\end{array}$ \\
\hline $\begin{array}{l}\text { Residence } \\
\text { Rural } \\
\text { Urban } \\
\end{array}$ & $\begin{array}{l}11(10.5) \\
26(24.8)\end{array}$ & $\begin{array}{l}8(7.6) \\
13(12.4)\end{array}$ & $\begin{array}{l}15(14.3) \\
32(30.5)\end{array}$ & $\begin{array}{l}0.437 \\
0.804\end{array}$ \\
\hline $\begin{array}{l}\text { Socio Economic Status } \\
\text { Lower } \\
\text { Middle } \\
\text { Upper }\end{array}$ & $\begin{array}{l}8(7.6) \\
11(10.5) \\
18(17.1)\end{array}$ & $\begin{array}{l}3(2.9) \\
8(7.6) \\
10(9.5)\end{array}$ & $\begin{array}{l}23(21.9) \\
17(16.2) \\
7(6.7)\end{array}$ & $\begin{array}{l}16.470 \\
\mathbf{0 . 0 0 2}^{*}\end{array}$ \\
\hline
\end{tabular}

\section{Discussion:-}

In the present study $53.3 \%$ of the mothers were belongs to the age group of $25-29$ years and $42.9 \%$ mothers were educated up to secondary school. A study on knowledge and attitude regarding immunization among the mothers of under five children at Mangalore shows that majority (50.3\%) mothers belongs to the age group between 26-30 years and majority $(45.3 \%)$ mothers have completed higher primary and high school education. ${ }^{6}$

$67.6 \%$ of mothers attending the maternal and child health centre were from urban area as compared to the $32.4 \%$ from rural as the health centre was situated in urban Nahan. $82.9 \%$ of mothers were non working and $90.5 \%$ were 
Hindu. Hindu is the most dominating religious community in sirmaur district which accounts $91 \%$ according to the latest census $2011 .^{7}$

The present study revealed that the $91.4 \%$ of the mothers had knowledge about the immunization and vaccine preventable diseases and only $45 \%$ were able to name a vaccine. Similar finding was found in a study where $85 \%$ mothers had knowledge about the vaccine preventable diseases. ${ }^{8}$ The source of information regarding vaccination among mothers were mainly (57.1\%) from the health workers and only $12 \%$ from media including TV, radio, newspaper. In a study conducted in Karachi, Pakistan among the mothers attending the paediatrics clinics, more than half of mothers $(54.5 \%)$ quoted health workers as their primary source of information regarding vaccination. ${ }^{9} 42 \%$ of the mothers gain the information related to time of each vaccination from health workers followed by $22 \%$ from maternal and child protection card. Another study found that half of the mothers $(50 \%)$ were told about the time of each vaccination by paramedical workers. ${ }^{10}$ In the present study $58 \%$ of mothers were aware of common side effects of the vaccination which includes fever, pain and redness at the site of injection.

None of the mothers had reported incomplete immunization or dropout in the present study. On the basis of scoring $44.8 \%$ of mothers had poor knowledge regarding immunization followed by $35.2 \%$ good knowledge. A study conducted in UP, India on assessment of knowledge of immunization among mothers of under five children shows that $66.6 \%$ of mothers had poor knowledge. ${ }^{11}$ Poor score was seen among mothers with low educational level as compare to the higher educational level. This present study shows the significant association between the lower socio-economic status and poor knowledge score among mothers. Similar results found in a study that the knowledge was significantly greater among mothers with a higher education level. ${ }^{12}$

\section{Conclusion:-}

The present study highlighted the knowledge regarding immunization among mothers attending maternal and child health centre. Almost all the mothers were aware regarding the vaccine preventable diseases. Major source of information regarding vaccination and time of each vaccine was health workers. The role of $\mathrm{MCH}$ centre as well as frontline workers in educating mothers and caregivers is very important and needs to be further strengthened. There is need of a health education session for mothers regarding vaccination schedule, vaccine preventable diseases, new vaccines introduced.

\section{Bibliography:-}

1. World Health Organization. Global Immunization Data. Available at: http://www.who.int/ immunization monitoring surveillance Global Immunization Data.2015 pdf.

2. WHO, UNICEF, World Bank. State of the world's vaccines and immunization, 3rd ed.Geneva, World Health Organization, 2009. Available at: http://www.unicef.org/ immunization/ files/ full report pdf.

3. Immunization handbook for Health workers. Ministry of Health and family welfare. Govt of India. 2011: 1-2.

4. Immunization Handbook for Medical officers; Dept of Health \& Family Welfare, Govt. Of India: 10-15.

5. Akmatov M, Kretzschmar M, Krämer A, Mikolajczyk R. Determinants of childhood vaccination coverage in Kazakhstan in a period of societal change: Implications for vaccination policies. Vaccine. 2007;25(10):17561763.

6. Mereena M, Sujatha R. A Study on Knowledge and Attitude Regarding Vaccines among Mothers of Under Five Children attending Pediatric OPD in a Selected Hospital at Mangalore. IOSR Journal of Nursing and Health Science. 2014;3(5):39-46.

7. District census handbook. Directorate of census operation Himachal Pradesh ministry of home affairs government of india. Census 2011.

8. Rachna K, Sheetal V. Awareness and knowledge of mothers of under five children regarding immunization in Ahmedabad. Healthline Journal, 2010(1); 12-15.

9. Gul S, Khaili R. Immunization knowledge and practices among the mothers attending paediatrics clinic in Karachi, Pakistan. Int J Adv Med. 2016 Aug;3(3):656-661.

10. Mabrouka A.M. Bofarraj. Knowledge, attitude and practices of mothers regarding immunization of infants and preschool children at Al-Beida City, Libya, 2008; Egypt J Pediatr Allergy Immunol 2011; 9(1):29-34.

11. Azmi F, Prakash R. Assessment of knowledge towards immunization among mothers of Under five children of UP, India: A quantitative approach. International journal of science and research;2015:1899.

12. Angelillo .A, Ricciardi .G, Rossi. P. Mothers and vaccination: knowledge, attitudes and behaviour in Italy. World Health Organization 1999 Bulletin of the World Health Organization, 1999;77(3):5. 